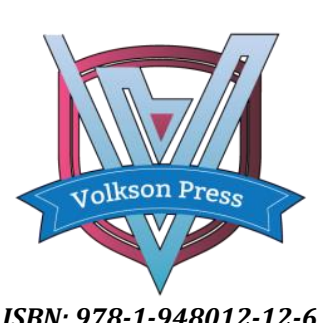

Contents List available at VOLKSON PRESS

New Materials and Intelligent Manufacturing (NMIM) DOI : http://doi.org/10.26480/icnmim.01.2018.315.318

Journal Homepage: https://topicsonchemeng.org.my/

ISBN: 978-1-948012-12-6

\title{
EXTRACTION AND ANTI-OXIDATION ACTIVITY OF POLYSACCHARIDES FROM LENTINAN
}

\author{
Men Cheng-Bai, Wu Mei-Fu, Zhou Hong-Li* \\ School of Chemistry and Pharmaceutical Engineering, Jilin Institute of Chemical Technology, Jilin 132022, China. \\ *Corresponding Author Email: zhl67@126.com
}

This is an open access article distributed under the Creative Commons Attribution License, which permits unrestricted use, distribution, and reproduction in any medium, provided the original work is properly cited.

\section{ARTICLE DETAILS}

Article History:

Received 26 June 2018

Accepted 2 July 2018

Available online 1 August 2018

\section{ABSTRACT}

The extraction and anti-oxidation activity of polysaccharides from Lentinan were studied by an orthogonal experimental design. The optimal extraction process was solid-liquid ratio $=1: 20, \mathrm{pH} 5,60{ }^{\circ} \mathrm{C}$ and extraction time $=3$ $\mathrm{h}$, with the extraction yield of $11.61 \%$. It was proved this extraction method was simple and available, and the crude polysaccharides had high antioxidant capacity.

\section{KEYWORDS}

Lentinan polysaccharides, Extraction, Anti-oxidation activity.

\section{INTRODUCTION}

Lentinula edodes is known in the folk as "mountain" and is the second most commonly cultivated edible mushroom in the world. This sweet and flat mushroom is also one Chinese specialty. The appetite loss and energy deficiency have been indicated [1]. The study of fungal polysaccharides as a drug began in 1950s and became an extensively attractive immunostimulant after 1960s. Lentinan is one of the most thoroughly studied polysaccharides. The immunomodulatory activity of lentinan is an important basis for its biological activity [2]. Lentinan has the functions of tumor resistance, viral resistance, immunity enhancement, and interferon formation stimulation [3]. Lentinan is curatively effective in treatment of gastric cancer, colon cancer, breast cancer, and lung cancer.

It can prolong the survival time of cancer patients, especially gastric cancer and colorectal cancer. Lentinan has become a research hotspot. There are several methods for lentinan extraction. Mariko Shida et al. extracted a heterogalactose and $\alpha-(1 \rightarrow 3)$ - D-glucan from the fruiting body of Lentinus edodes by using 3\% trichloroacetic acid and $1 \mathrm{~mol} / \mathrm{L} \mathrm{NaOH}$ solution [4]. The yield with an ultrasonic method was $7.24 \%$ and showed high antioxidant activity [5]. Chuancong Peng et al. used response surface methodology to optimize the process of ultrasound-assisted hot water extraction of lentinan and found the polysaccharide extract could modestly eliminate DPPH free radicals in a dose-dependent way [6]. Jinyuan Cai et al. found the scavenging effects of lentinan extracted by microwave-assisted methods on 02 - and $\cdot \mathrm{OH}$ were enhanced with the increasing concentration [7]. Lei Huang found the lentinan polysaccharides with larger relative molecular mass had stronger antioxidant capacity [8].

To prevent the destruction of polysaccharides by the extraction conditions, we used the orthogonal experimental design to examine the classic water extraction and alcohol precipitation method $[9,10]$ and to identify the optimal extraction conditions. Starting from the scavenging effect of $\mathrm{H}_{2} \mathrm{O}_{2}$, we explored the antioxidant activity in vitro for further development and provided a theoretical basis.

\section{EXPERIMENTAL}

\section{$2.1 \quad$ Instruments and reagents}

An SHB-IIIA circulating water multipurpose vacuum pump (Zhengzhou Great Wall Branch Industry \& Trade Co., Ltd.); an RE-52A type rotary evaporator (Shanghai Ya Rong Biochemical Instrument Factory); a 725 ultraviolet visible spectrophotometer (Shandong Gaomi Rainbow Analysis Instrument Co., Ltd.) were used here. Other instruments included a centrifugal sedimentation machine; a vacuum drying box; a fast mixer; an electric drying oven with forced convection; a digital constant temperature water Bathing pan; an FA-2004 analytical balance (Shanghai Fine Science and Technology Instrument Factory).

Lentinus edodes (purchased from supermarket), $\mathrm{NaOH}$, light petroleum, phenol, sulfuric acid, 95\% ethanol, glucose, phosphoric acid, hydrogen peroxide and other reagents were all analytically pure.

\subsection{Analysis and detection of Lentinus edodes polysaccharides}

\subsubsection{Raw material pretreatment}

The fresh Lentinus edodes was purified and dried at $45-50{ }^{\circ} \mathrm{C}$ to constant mass [11]. The materials were crushed at $24000 \mathrm{r} / \mathrm{min}$ for $1 \mathrm{~min}$, were sifted over 40 mesh sieve and put aside.

\subsubsection{Basic procedures}

Lentinus edodes powder was degreased $\rightarrow$ extracted in $\mathrm{HCl}$ solution and $\mathrm{NaOH}$ solution $\rightarrow$ centrifuged at $4000 \mathrm{r} / \mathrm{min}$ for $15 \mathrm{~min} \rightarrow$ the extract supernatant was concentrated at $60{ }^{\circ} \mathrm{C}$ to $1 / 4 \rightarrow$ precipitated in $90 \%$ ethanol overnight $\rightarrow$ centrifuged at $8000 \mathrm{r} / \mathrm{min}$ for $10 \mathrm{~min} \rightarrow$ Lentinus edodes crude polysaccharides were obtained $\rightarrow$ precipitated, dried and made into powder $\rightarrow$ precipitation solution. The polysaccharides were measured in distilled water at $490 \mathrm{~nm}$.

\subsubsection{Measurement of polysaccharide content}

Polysaccharides were measured by a phenol-sulfuric acid method [12]. A series of standard glucose solutions $(0.5 \mathrm{~mL}), 5 \%$ phenol reagent $(1 \mathrm{~mL})$, and concentrated sulfuric acid $(3.5 \mathrm{~mL})$ were put into a water bath at 40 ${ }^{\circ} \mathrm{C}$ for $30 \mathrm{~min}$, and then cooled for $15 \mathrm{~min}$. Absorbance was measured at $490 \mathrm{~nm}$. 


\subsection{1} rate

\section{Effect of single-factor test on the polysaccharide extraction}

The single-factor test was focused on the measurement of polysaccharides, especially $\mathrm{pH}$, and on the extraction temperature in order to prevent the destruction of polysaccharides [13-15].

2.3.1.1 The material to liquid ratio. The material to liquid ration was determined by adding $2 \%$ activated carbon into distilled water at $90{ }^{\circ} \mathrm{C}$ and refluxed for 1 hour after drying to constant weight of Lentinus edodes at a ratio of 1: 20:1:1:40:40 to 1: 1: 100. After that, the mixtures were centrifuged at $4000 \mathrm{r} / \mathrm{min}$ for $15 \mathrm{~min}$. The extract filtrate $(2 \mathrm{~mL})$ was dissolved in a $50-\mathrm{mL}$ volumetric bottle for measurement of absorbance. The polysaccharide extraction rate was determined.

2.3.1.2 The $\mathrm{pH}$ was inspected at the feed liquid ratio of 1: 60. The $\mathrm{pH}$ was adjusted by $5 \% \mathrm{HCl}$ or $\mathrm{NaOH}$ to $3,5,7,9$ or 11 . The other conditions were the same as section 2.3.1.1.

2.3.1.3 2.3.1.3 The extraction temperature of the water bath was 60,70 , $80,90,100{ }^{\circ} \mathrm{C}$, and the rest conditions were the same as section 2.3.1.2.

2.3.1.4 2.3.1.4 The extraction time was $1,2,3,4,5 \mathrm{~h}$, and the other conditions were the same as section 2.3.1.2.

2.3.1.5 2.3.1.5 The filter residue was repeated twice according to the above method and the other conditions were the same as section 2.3.1.2.

\subsubsection{Orthogonal assays}

Many factors affect the extraction rate of polysaccharides from Lentinus edodes, such as material comminution degree, solid-liquid ratio, $\mathrm{pH}$, time, and temperature. On the basis of single-factor experiments, the orthogonality was used to optimize the extraction conditions according to the influence laws of these factors (Table 1) [16].

Table1: The orthogonal design of factors and levels

\begin{tabular}{|c|c|c|c|c|}
\hline No. & $\begin{array}{l}\text { A } \\
\text { solid to liquid } \\
\text { ratio }\end{array}$ & $\begin{array}{l}\mathrm{B} \\
\mathrm{pH}\end{array}$ & $\begin{array}{l}\mathrm{C} \\
\text { temperatu } \\
\text { re }\end{array}$ & $\begin{array}{l}\mathrm{D} \\
\text { time }\end{array}$ \\
\hline 1 & $1: 20$ & 5 & 60 & 3 \\
\hline 2 & $1: 40$ & 7 & 70 & 4 \\
\hline 3 & $1: 60$ & 9 & 80 & 5 \\
\hline
\end{tabular}

\section{4}

\section{Antioxidant assays}

The scavenging effect of $\mathrm{H} 2 \mathrm{O} 2$ was tested to examine the antioxidant activity in vitro of polysaccharides. Antioxidative activity of lentinan in vitro within $0.2-1.0 \mathrm{mg} / \mathrm{mL}$ was measured using the $\mathrm{H}_{2} \mathrm{O}_{2}$ method.

Each time, $2.8 \mathrm{~mL}$ of a $0.5 \mathrm{mmol} / \mathrm{L} \mathrm{H}_{2} \mathrm{O}_{2}$ solution was added into a 50 $\mathrm{mmol} / \mathrm{l}$ phosphate buffer $(\mathrm{pH}=7.4)$ in a $10 \mathrm{~mL}$ stoppered tube, which was added with $0.4 \mathrm{~mL}$ of $0.2,0.4,0.6,0.8$, or $1.0 \mathrm{mg} / \mathrm{mL}$ polysaccharide solution. After $10 \mathrm{~min}$ of reaction, the Ai value at $230 \mathrm{~nm}$ was measured. Each sample was conducted in triplicate. A blank control with the same volume of distilled water instead of the sample was prepared. The clearance rate was calculated as follows:

$$
\mathrm{S} / \%=[(\mathrm{A} 0-\mathrm{Ai}) / \mathrm{A} 0] \times 100
$$

where A0 -- absorbance without any sample; Ai -- absorbance of a sample.

\section{RESULTS AND ANALYSIS}

\subsection{Extraction of Lentinan edodes}

\subsubsection{Measurement of Polysaccharide Content}

In the range of $0.02092-0.1255 \mathrm{mg} / \mathrm{mL}$, the absorbance was plotted on the $\mathrm{Y}$-axis and the glucose content on the $\mathrm{X}$-axis. The regression equation was $y=7.3928 x+0.0085\left(r^{2}=0.9998, n=6\right)$.
3.1.2 Influence of solid-liquid ratio on polysaccharide extraction rate

With the increase of the solid to liquid ratio, the extraction yield of polysaccharides was also gradually improved (Figure 1a). When the solid to liquid ratio was $1: 40$, the extraction rate maximized, and after the ratio of $1: 60$, the yield of polysaccharides was slightly reduced. Theoretically, the total amount of sugar in a certain quantity of shiitake mushrooms was constant. With the increase of the extraction solution, the total amounts of polysaccharides in the solvent and the raw materials rose and decreased respectively, resulting in a smaller concentration difference. According to the diffusion law, the diffusion rate decreases and gradually reaches a basic balance. Considering that the pressure in the subsequent concentration step should be reduced, we selected the solid to liquid ratio of $1: 20,1: 40$, and $1: 60$ as the single factor for orthogonal tests.

\subsubsection{Effect of pH on extraction rate of polysaccharides}

With the increase of $\mathrm{pH}$, the extraction yield of polysaccharides was almost unchanged (Figure 1b). When at $\mathrm{pH} 11$, the polysaccharide extraction rate was the highest, but excessive alkalinity may cause the destruction of lentinan. Therefore, $\mathrm{pH} \mathrm{5,} \mathrm{7,} \mathrm{and} 9$ were selected as the factor in orthogonal tests.

\subsubsection{Effect of extraction temperature on extraction rate of polysaccharide}

The extraction rate of polysaccharide gradually increased with temperature rise (Figure 1c), but decreased with, further temperature increase. In fact, a higher temperature requires more energy consumption and more easily destroys the polysaccharide structure. Therefore, 60, 70, and 80 were selected as single factor for orthogonal tests.

\subsubsection{Effect of extraction time on polysaccharide extraction rate}

With the prolonging of extraction time, the extraction rate of polysaccharide increased rapidly (Figure $1 \mathrm{~d}$ ), but when the extraction time exceeded 3 hours, the extraction rate was not significantly increased and even slightly decreased. This result was mainly due to the fact that as the extraction time was prolonged, a larger polysaccharide concentration in the solvent led to smaller difference from the polysaccharide concentration in the solid raw material powder, and a slower diffusion rate basically under equilibrium. Thus, we chose $3,4,5 \mathrm{~h}$ as a single factor in the orthogonal tests.

\subsubsection{Effect of extraction times on extraction rate of polysaccharides}

Still some polysaccharide components were not extracted after one extraction (Figure 1e). The yields can be improved after two extractions, but the yields in the third time were very small and can be ignored. Considering that each extraction was time-consuming, we set the extraction time as once.
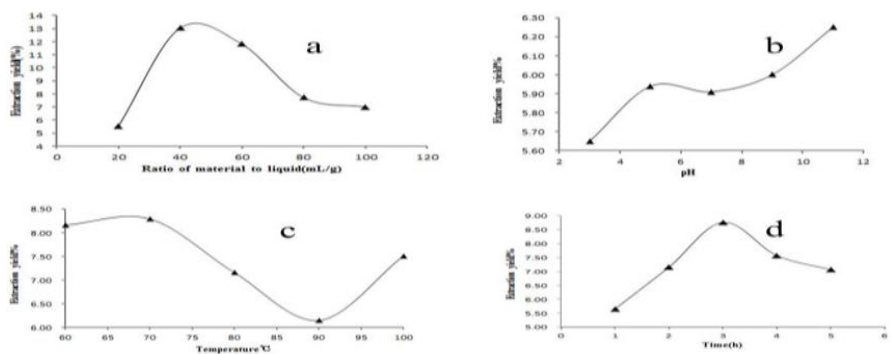

Figure 1: Effects of various factors on polysaccaride extraction

\subsubsection{Orthogonal test of polysaccharide extraction from Mushrooms}

According to the design of the factor levels, mushrooms were dried (each $2 \mathrm{~g}$ ), and based on the L9 (3) 4 orthogonal test table, the polysaccharide extraction yield was determined (Table 2). 
Table 2: Results of orthogonal tests of Lentinan extraction

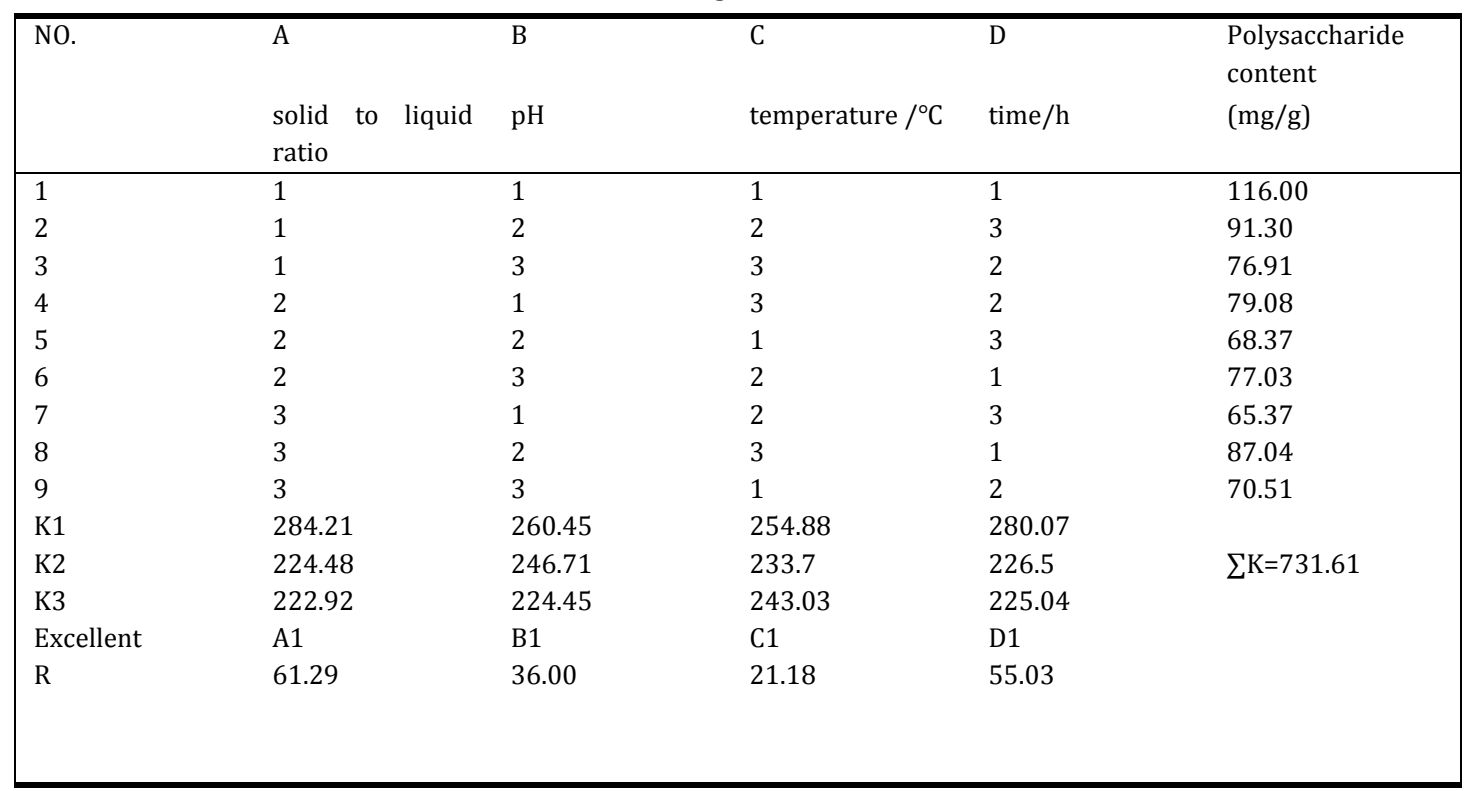

The extreme difference in Table 2 indicates that the influence factors on the extraction rate ranked in the order of $\mathrm{A}>\mathrm{D}>\mathrm{B}>\mathrm{C}$, and the extraction rate of polysaccharide was maximized in the combination of A1D1B1C1.

Above all, fresh mushrooms ( $40 \mathrm{~g}$ ) were washed, dried, and shredded, and the conditions were: mushrooms: distilled water ratio $=1: 20, \mathrm{pH} 5,6{ }^{\circ} \mathrm{C}$, and extraction time $=3 \mathrm{~h}$. The resulting mixtures were filtrated and concentrated, which generated $4.0 \mathrm{~g}$ of mushroom polysaccharide extract.

\subsection{Antioxidant test}

Table 3 shows that lentinan has certain antioxidant activity and removal ability within a certain range, which are improved with the increase of polysaccharide concentration. Moreover, the removing ability is linearly related with polysaccharide concentration. When the concentration is 0.2 $\mathrm{mg} / \mathrm{ml}$, the removal rate of polysaccharide exceeds $50 \%$.

Table 3: Results of anti-oxidation activity in vitro (mean $\pm \mathrm{s}, \mathrm{n}=3$ )

\begin{tabular}{|ll|}
\hline Concentration $(\mathrm{mg} / \mathrm{mL})$ & $\mathrm{H}_{2} \mathrm{O}_{2}$ clearance rate $(\%)$ \\
\hline 0.2 & $68.29 \pm 0.30$ \\
0.4 & $70.12 \pm 0.54$ \\
0.6 & $76.34 \pm 0.23$ \\
0.8 & $84.12 \pm 0.29$ \\
1.0 & $89.99 \pm 0.35$ \\
\hline
\end{tabular}

\section{CONCLUSIONS}

Polysaccharides were extracted by hot water decoction. The orthogonal design involving four factors of extraction temperature, $\mathrm{pH}$, time and material-liquid ratio was performed. The optimal process was: $60{ }^{\circ} \mathrm{C}, \mathrm{pH}$ 5 , extraction time $=3 \mathrm{~h}$, and solid-liquid ratio $=1: 20$. As the polysaccharide concentrations increased, the $\mathrm{H} 2 \mathrm{O} 2$ removing ability of lentinan was also improved linearly, indicating lentinan has modest anti-oxidation activity.

\section{ACKNOWLEDGMENTS}

This study was financed by Jilin provincial development and Reform Commission (Grant No. 2017C044).

\section{REFERENCES}

[1] Fang-Liang, L.I., Zhao, L.D., Gao, Y. 2011. Comparison between Antioxidant Activities of Polysaccharides Extracts from Two Kinds of Edible Mushroom [J]. Hunan Agricultural Sciences.
[2] Lv, G.Y., Fan, L.F., Zhang, Z.F. 2009. Development of research on lentinan [J]. Acta Agriculturae Zhejiangensis, 183-188.

[3] Lin, N., Zhong, Y.G., Wang, S.Q. 2007. Review on Advancement of Polysaccharide From Lentinula Edodes [J]. Food Research \& Development.

[4] Shida, M., Haryu, K., Matsuda, K. 1975. On the water-soluble heterogalactan from the fruit bodies of lentinus edodes [J]. Carbohydrate Research, 41 (1), 211-218.

[5] Zou, L.W., Zhao, M.M., You, L.J. 2013. Optimization of ultrasonic extraction of polysaccharides from Lentinan and there bioactive activities [J]. Science and Technology of Food Industry, 34 (19), 177-182.

[6] Peng, C.C., Kong, J., You, L.J. 2011. Optimization of Ultrasonicassisted Extraction Technology of Lentinan Polysaccharides by Response Surface Methodology and its Antioxidant Activity [J]. Modern Food Science and Technology, 27 (2), 452-456.

[7] Cai, J., Sun, S., Xinhai, L.I. 2016. Optimization of MicrowaveAssisted Extraction of Lentinan Using Uniform Design and Orthogonal Design [J]. Journal of Henan University of Technology.

[8] Huang, L. 2013. Study on antioxidation and inhibition mechanism of Lentinula edodes polysaccharide [J]. Guangdong Agricultural Sciences.

[9] Zhang, Y., Zhang, S., Wang, F. 2015. Review on Extraction Methods of Plant Polysaccharide of These Years[J]. Farm Products Processing.

[10] Zhao, J.G. 2011. Study on Extraction Process of Polysaccharides from Semen Euryales by Ultrasonic-assisted Method [J]. Medicinal Plant, (4).

[11] Liao, R.Q., Zhong, Q.P., Lan-Xian, X.U. 2015. The Extraction Process of Polysaccharide from Loranthus delavayi Van Tiegh [J]. Food Research and Development.

[12] Chong-Long, L.I., Jia, Y.C. 2016. Study on the Optimization of Extraction Technology of Polysaccharide from Thymus Quinquecostatus [J]. Chemical World.

[13] Cai, J., Sun, S., Xinhai, L.I. 2016. Optimization of MicrowaveAssisted Extraction of Lentinan Using Uniform Design and Orthogonal Design[J]. Journal of Henan University of Technology.

[14] Zhang, M., Qi, Y., Yang, H. 2016. Optimized Extraction Condition of Lentinan and Its Antibacterial and Antioxidant Activity [J]. Chinese Agricultural Science Bulletin.

[15] Dai, J. 2012. The effects of ultrasonic parameters on the 
antioxidation activity of polysaccharides from Saposhnikovia divaricate [J]. Applied Acoustics.

[16] Peng, J.L., Mao, J., Huang, G.D. 2012. Study on antioxidant activity of polysaccharide from Chinese Rice Wine in vitro [J]. Science and Technology of Food Industry, 33 (20), 94-97. 